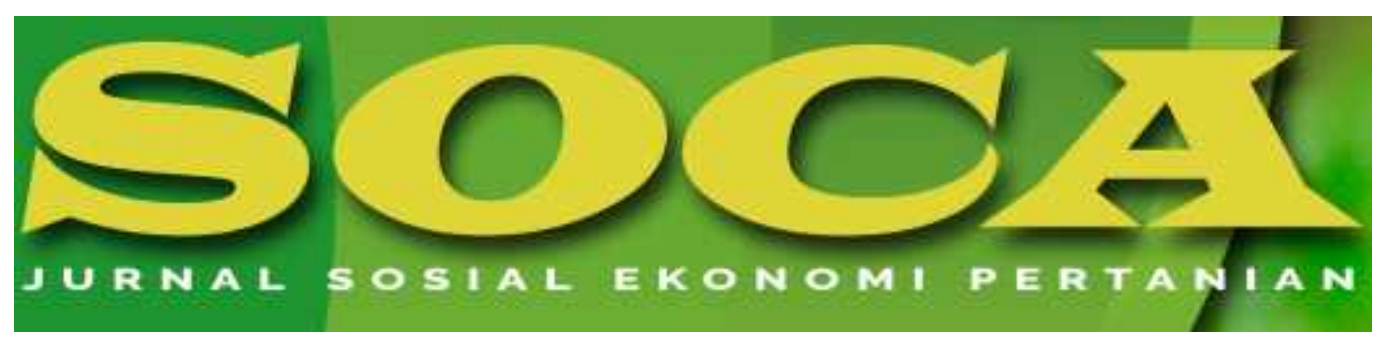

https://ojs.unud.ac.id/index.php/soca

\title{
PERAN BALAI PENGELOLAAN HUTAN MANGROVE WILAYAH I BALI DALAM PENGOLAHAN HASIL HUTAN MANGROVE BERBASIS PEMBERDAYAAN MASYARAKAT LOKAL
}

\author{
Komang Dean Ananda ${ }^{1}$, Pande Komang Suparyana ${ }^{2}$ dan \\ F. Maftukhakh Hilmya Nada ${ }^{3}$ \\ ${ }^{1}$ Universitas Mahasaraswati, Denpasar \\ 2Universitas Mataram \\ ${ }^{3}$ Universitas Muhammadiyah, Malang \\ Email korespondensi: dean.ananda@unmas.ac.id, panko.suparyana@gmail.com, \\ maftukhafirda@gmail.com, Telepon/HP:085700485060
}

\begin{tabular}{l} 
Kata Kunci: \\
mangrove, \\
pengolahan, \\
hasil hutan \\
bukan kayu, \\
produk \\
mangrove \\
\hline
\end{tabular}

\begin{abstract}
Abstrak
Laju degradasi mangrove semakin meningkat seiring dengan maraknya alih fungsi lahan (konversi) untuk tujuan tertentu, maupun pemanfaatan hasil hutan mangrove yang berorientasi bukan pada hasil non kayu melainkan pada hasil kayunya. Pengolahan hasil hutan mangrove yang memiliki nilai ekonomi seyogyanya menjadi salah satu bentuk pelestarian dan keberlanjutan mangrove. Balai Pengelolaan Hutan Mangrove (BPHM) Wil. 1 Bali, menjadi sebuah poros penggerak dalam pengolahan hasil hutan mangrove khususnya Hasil Hutan Bukan Kayu (HHBK) di Mangrove Tahura Ngurah Rai, yang memberdayakan masyarakat lokal dengan pelatihan skill untuk mengolah produk mangrove menjadi produk yang benilai ekonomi.

Penelitian ini dilaksanakan di Balai Pengelolaan Hutan Mangrove Wil. I, Suwung Kauh, Denpasar, Bali. Metode yang digunakan adalah dengan mengobservasi mangrove secara random sampling yang kemudian akan dipanen berdasar pada karakteristik siap panen dan waktu panen. Buah mangrove yang dipanen antara lain; 1) Sonneratia caseolaris (Pidada); 2) Bruguiera gymnorrizha (Lindur); 3) Xylocharpus granatum (Nyirih). Buah-buah tersebut akan diolah menjadi produk antara lain, sirup, sabun, dodol, tepung, beras, dan lulur. Pengolahan HHBK mangrove dilakukan melalui pemberdayaan masyarakat lokal.

Pemanfaatan mangrove lebih digalakkan pada sektor Hasil Hutan Bukan Kayu yaitu dengan memanfaatkan buah dan daun mangrove, pamanfaatan ekowisata, serta
\end{abstract}


pemanfaatan silvofishery. BPHM WIL I. Bali berperan penting dalam menjaga kelestarian dan keberlanjutan vegetasi Mangrove Tahura Ngurah Rai. Salah satu upaya yang dilakukan adalah pengolahan terhadap Hasil Hutan Bukan Kayu (HHBK) mangrove, yaitu dapat berupa buah maupun daunnya.

\title{
THE ROLE OF THE BALAI PENGELOLAAN HUTAN MANGROVE WILAYAH 1 BALI IN THE PROCESSING OF MANGROVE FOREST PRODUCTS BASED ON LOCAL COMMUNITY EMPOWERMENT
}

Keywords:
mangrove,
processing, non-
timber forest
products,
mangrove
product

\section{Keywords:}

mangrove, processing, nontimber forest product

\begin{abstract}
Abstrak
Mangrove degradation is increasing along the proliferation of purposely land conversion. The utilization of the products of mangrove forests are oriented to the timber. Processing of mangrove products that have economic value should be a form of mangrove conservation and sustainability. Balai Pengelolaan Hutan Mangrove (BPHM) Wilayah 1 Bali, has become a center to processing mangrove forest products, especially non-timber products in Mangrove Tahura Ngurah Rai, which empowers local communities with skill training to process mangrove products into the economic value products. This research was carried out at the Mangrove Tahura Ngurah Rai. The method used is by observing mangroves by random sampling which will then be harvested based on the characteristics of ready harvest and harvest time. Mangroves that have been harvested, among others Sonneratia caseolaris, Bruguiera gymnorrizha, and Xylocharpus granatum. Those mangrove products will be processed into products such as syrup, soap, dodol, flour, rice, and scrubs. The processing of non-timber products is done through empowering local communities. The utilization of mangroves is more focused on the nontimber of forest products by utilizing mangrove fruits and leaves, ecotourism utilization, and silvofishery. BPHM I. Bali has an important role in maintaining the sustainability of the Mangrove Tahura Ngurah Rai.
\end{abstract}

How to Cite (APA 6th Style):

Ananda, K. D., Suparyana, P. K., \& Nada, F. M. H. (2019). Peran Balai Pengelolaan Hutan Mangrove Wilayah I Bali Dalam Pengolahan Hasil Hutan Mangrove Berbasis Pemberdayaan Masyarakat Lokal. SOCA: Jurnal Sosial Ekonomi Pertanian, 13(3), 331-339. https://doi.org/https://doi.org/10.24843/SOCA.2019.v13.i03.p04

\section{PENDAHULUAN}

Indonesia memiliki potensi mangrove terluas di dunia, yakni seperempat dari total mangrove dunia (18 juta hektar), yaitu sekitar 3,7 juta hektar yang tersebar hampir di seluruh kepulauan di Indonesia. 
Mangrove berperan penting dalam melindungi lingkungan, antara lain dari melindungi daratan dari abrasi, mengontrol intrusi air laut dan sebagai tempat berkembangbiak biota laut seperti ikan dan kepiting. Sumberdaya mangrove di Indonesia sangat tinggi baik flora maupun fauna. Sedikitnya terdapat 63 jenis mangrove antara lain 47 pohon, 5 perdu, 9 herba dan 2 termasuk parasit (Kusmana, 1993). Namun, laju degradasi mangrove semakin meningkat seiring dengan adanya eksploitasi terutama alih fungsi lahan (konversi) untuk tujuan lain seperti pembuatan tambak dan pembangunan pemukiman, maupun pemanfaatan hasil hutan mangrove yang berorientasi bukan pada hasil non kayu melainkan pada hasil kayunya.

Dengan kondisi demikian, maka diperlukan pengelolaan yang khusus untuk menjaga kelestariannya. Pengelolaan yang dilakukan adalah sebagai upaya perbaikan (rehabilitasi) dan konservasi oleh berbagai pihak selain yang utama adalah meningkatkan pemahaman dan kepedulian masyarakat terhadap mangrove. Selain itu, pemanfaatan hasil hutan mangrove yang kemudian diolah sehingga bernilai ekonomi dapat mendukung upaya keberlanjutan (sustainability) dan kelestarian (preservation) mangrove itu sendiri.

Mangrove TAHURA Ngurah Rai menjadi destinasi wisata mangrove yang banyak dikunjungi tidak hanya oleh turis domestik melainkan juga turis mancanegara. Luasan mangrove telah bertambah seiring dengan keberhasilan penghijauan yang dilakukan di wilayah TAHURA Ngurah Rai menjadi 3.375,5 Ha (Sundra, 2016). Dengan luasan tutupan vegetasi yang demikian besar, maka produksi buah mangrove juga melimpah, namun belum terolah dengan baik.

Dalam sebuah upaya pengolahan hasil hutan mangrove agar bernilai ekonomi, perlu memperhatikan teknik pengolahannya, metode, pengemasan terhadap produk olahan, serta pemasaran yang tepat. Selain itu, pelatihan (training) terhadap SDM yang akan terlibat menjadi fokus utama dikarenakan dalam proses pengolahan tersebut dibutuhkan sebuah keahlian (skill) tertentu yang dapat mendukung keberhasilan produk mangrove itu sendiri.

Menurut Sundra (2016), Mangrove TAHURA Ngurah Rai belum ada kejelasan terkait pemanfaatannya oleh pemangku kepentingan yang terkait. Selain itu berdasarkan penelitian yang dilakukan oleh Manurung, dkk. (2016) potensi mangrove TAHURA Ngurah Rai lebih mengarah pada potensi fisik, yakni diantaranya panorama Hutan Mangrove, Tracking Mangrove $1.400 \mathrm{~m}$, Bird Tower, serta kawasan konservasi bagi hutan mangrove dan aneka fauna seperti; burung, kepiting, ikan, dan biawak.

Penelitian ini menghadirkan ide dan atau metode pengolahan hasil hutan bukan kayu (HHBK) sebagai bentuk pemanfaatan mangrove dan menawarkan potensi biotik mangrove melalui pengolahan buah maupun daun mangrove menjadi produk bernilai ekonomi.

Balai Pengelolaan Hutan Mangrove (BPHM) Wil. 1 Bali, menjadi sebuat poros penggerak dalam pengolahan hasil hutan mangrove khususnya Hasil Hutan Bukan Kayu (HHBK) di Mangrove Tahura Ngurah Rai.

\section{METODE PENELITIAN}

Penelitian ini dilaksanakan di Balai Pengelolaan Hutan Mangrove Wil. I pada posisi $8^{\circ} 43^{\prime} 30^{\prime \prime} \mathrm{LS} \quad 115^{\circ} 11^{\prime} 38^{\prime \prime} \mathrm{BT}$ dengan alamat di Jalan By Pass Ngurah Rai 
kilometer 21 Suwung Kauh, Denpasar, Bali. Metode yang digunakan adalah dengan mengobservasi mangrove secara randon sampling yang kemudian akan dipanen berdasar pada karakteristik siap panen dan waktu panen. Pemanenan dilakukan berdasarkan zonasi mangrove sesuai dengan peruntukannya. Pengolahan hasil hutan mangrove dilakukan di tempat pengolahan yang sudah disediakan. Buah mangrove yang dipanen antara lain; Sonneratia caseolaris (Pidada), yang dapat diolah menjadi dodol, sirup, serta sabun; 2) Bruguiera gymnorrizha (Lindur), yang dapat diolah menjadi tepung dan beras; serta 3) Xylocharpus granatum (Nyirih), yang dapat diolah menjadi lulur.

\section{HASIL DAN PEMBAHASAN}

Balai Pengelolaan Hutan Mangrove Wilayah I, Bali memiliki tugas pokok dalam hal penyusunan rencana dan program, pengembangan kelembagaan, pengelolaan sistem informasi, pemantauan dan evaluasi pengelolaan hutan mangrove. Dikarenakan hal tersebut di atas, BPHM Wilayah I, Bali ini dapat menjadi sarana pembelajaran serta wadah bagi kaum pelajar ataupun wisatawan yang membutuhkan informasi mengenai hutan mangrove. BPHM Wilayah I, Bali memiliki wilayah kerja yakni Pulau Jawa dan Madura, Pulau Bali, Pulau NTT, Pulau NTB, Pulau Sulawesi, Pulau Maluku, dan Pulau Papua. Selain itu terdapat pula BPHM Wilayah II, Sumatera Utara dengan wilayah kerja Pulau Sumatra dan Pulau Kalimantan. Wilayah kerja yang dikelola BPHM Wilayah I, Bali adalah \pm 2.296 .136$ $\mathrm{Ha}$, dan luas wilayah kerja di Pulau Bali adalah $\pm 2.215 \mathrm{Ha}$.

BPHM Wil. I Bali telah melaksanakan berbagai kegiatan program dalam upaya pelestarian Mangrove Tahura Ngurah Rai. Salah satunya adalah kontribusi nyata dalam pemberdayaan masyarakat / petani (mangrove) lokal yang dilibatkan secara langsung untuk melakukan pengolahan hasil hutan mangrove. Dalam sebuah kegiatan rutin berupa pameran, expo, exhibition, atau berbagai event baik regional, nasional, maupun internasional telah melibatkan masyarakat lokal yang telah lebih dulu dibekali sebuah pelatihan khusus untuk memiliki skill mengolah produk mentah menjadi sebuah produk layak jual dengan daya tarik dan kualitas yang baik.

Sebelum melakukan pengolahan tersebut, terlebih dahulu dilakukan iedntifikasi jenis mangrove sebelum dilakukan pemanenan terhadap buah-buah mangrove yang akan diolah menjadi produk bernilai ekonomi. Cara pengenalan jenis mangrove dapat dilihat dari: (1) bentuk pohon, (2) bentuk buah, (3) bentuk akar, (4) bentuk dan struktur daun, (5) rangkaian bunga, dan (6) habitat tempat tumbuhnya. Adapun jenis-jenis mangrove yang ditemukan di TAHURA Ngurah Rai, Bali antara lain sebagai berikut:

Tabel 1. Jenis-Jenis Mangrove di TAHURA Ngurah Rai

\begin{tabular}{llllll}
\hline NO & GENUS & \multicolumn{1}{c}{ SPESIES } & \multicolumn{2}{c}{ CIRI-CIRI } & \\
\hline 1. & Rhizophora & $\begin{array}{l}\text { Rhizophora } \\
\text { mucronata }\end{array}$ & - & Rangkaian & bunga \\
& & - & berjumlah 4-8 & \\
& & - & Daun lebar & \\
& & - & Ranganjang & \\
\hline & & Rhizophora stylosa & & bunga \\
& & & & \\
\end{tabular}




\begin{tabular}{|c|c|c|}
\hline & Rhizophora apiculata & $\begin{array}{ll}\text { - } & \text { Rangkaian } \\
\text { berjumlah } 2\end{array}$ \\
\hline \multirow[t]{3}{*}{ Bruguiera } & $\begin{array}{l}\text { Bruguiera } \\
\text { gymnorrhiza }\end{array}$ & $\begin{array}{ll}\text { - } & \text { Rangkaian } \\
\text { berjumlah } 1 \\
\text { - } \\
\text { Kelopak } \\
\text { merah }\end{array}$ \\
\hline & Bruguiera parviflora & $\begin{array}{ll}\text { - } & \text { Rangkaian } \\
\text { - } & \text { berjumlah 3-4 } \\
\text { Kelopak berwarna putih }\end{array}$ \\
\hline & Bruguiera cylindrica & $\begin{array}{l}\text { - } \quad \text { Rangkaian bunga } \\
\text { berjumlah } 3 \\
\text { - } \quad \text { Kelopak berwarna putih }\end{array}$ \\
\hline \multirow[t]{2}{*}{ 3. Ceriops } & Ceriops tagal & $\begin{array}{l}\text { - Buah menghadap ke } \\
\text { bawah } \\
\text { - Kotiledon berwarna } \\
\text { kuning }\end{array}$ \\
\hline & Ceriops decandra & $\begin{array}{l}\text { - } \begin{array}{l}\text { Buah menghadap ke } \\
\text { atas } \\
\text { - Kotiledon berwarna } \\
\text { merah }\end{array} \\
\end{array}$ \\
\hline \multirow[t]{2}{*}{ 4. Sonneratia } & Sonneratia alba & $\begin{array}{ll}\text { - } & \text { Benang sari berwarna } \\
& \text { putih } \\
\text { - } & \text { Tangkai buah pendek } \\
\text { - } & \text { Kelopak buah } \\
& \text { menghadap ke bawah }\end{array}$ \\
\hline & Sonneratia caseolaris & $\begin{array}{ll}\text { - } & \text { Benang sari berwarna } \\
\text { merah } & \\
\text { - } & \text { Tangkai buah panjang } \\
\text { - } & \text { Kelopak buah ke atas }\end{array}$ \\
\hline \multirow[t]{3}{*}{ 5. Avicennia } & Avicennia marina & $\begin{array}{ll}\text { - } & \begin{array}{l}\text { Ujung daun agak } \\
\text { membulat } \\
\text { berbentuk oval }\end{array}\end{array}$ \\
\hline & Avicennia alba & $\begin{array}{l}\text { - Ujung daun lancip dan } \\
\text { berbentuk lanset }\end{array}$ \\
\hline & Avicennia lanata & $\begin{array}{l}\text { Daun tebal, berbulu, } \\
\text { berbentuk oval, bagian } \\
\text { bawah berwarna lebih } \\
\text { terang }\end{array}$ \\
\hline \multirow[t]{2}{*}{ 6. Xylocarpus } & Xylocarpus granatum & Bentuk daun oval \\
\hline & $\begin{array}{l}\text { Xylocarpus } \\
\text { mollucensis }\end{array}$ & Bentuk daun lanset \\
\hline \multirow[t]{2}{*}{ 7. Aegiceras } & $\begin{array}{l}\text { Aegiceras } \\
\text { corniculatum }\end{array}$ & $\begin{array}{l}\text { - Bunga atau buah } \\
\text { tersusun seperti payung } \\
\text { - Buah berbentuk } \\
\text { curve/melengkung }\end{array}$ \\
\hline & Aegiceras floridum & $\begin{array}{ll}\text { - } & \text { Bungan atau buah } \\
\text { tersusun seperti tandan } \\
\text { - }\end{array}$ \\
\hline \multirow[t]{2}{*}{ 8. Lumnitzera } & Lumnitzera racemosa & Bunga berwarna putih \\
\hline & Lumnitzera littorea & Bunga berwarna merah \\
\hline
\end{tabular}

Sumber: Kitamura, et al., 2003

Pentingnya mengetahui spesies mangrove bertujuan untuk memastikan metode pemanenan serta pengolahan seperti apa yang diharapkan. Adapun waktu panen setiap jenis mangrove berbeda-beda. Waktu tersebut dapat dilihat pada Tabel 2. 
Tabel 2. Bulan-Bulan Panen Buah Mangrove

\begin{tabular}{|l|l|l|l|l|l|l|l|l|l|l|l|}
\hline \multicolumn{1}{|c|}{ Jenis } & Jan & Feb & Mar & Apr & Mei & Jun & Jul & Agt & Sep & Okt & Nov \\
\hline Rh.mucronata & & & & & & & & & & & \\
\hline Rh.apiculata & & & & & & & & & & & \\
\hline X.granatum & & & & & & & & & & & \\
\hline A.marina & & & & & & & & & & & \\
\hline C. tagal & & & & & & & & & & & \\
\hline B.gymnorrhiza & & & & & & & & & & & \\
\hline S.alba & & & & & & & & & & & \\
\hline
\end{tabular}

Sumber: Taniguchi et al. 1999

Selain waktu panen, penting pula memahami karakteristik buah mangrove yang telah masak dan layak untuk dipanen. Adapun ciri-ciri tersebut dijelaskan dalam Tabel 3.

Tabel 3. Karakteristik Buah yang Masak

\begin{tabular}{|l|l|}
\hline Spesies & Karakteristik Propagul dan Buah Masak \\
\hline Rhizophora mucronata & $\begin{array}{l}\text { Propagul (hipokotil) berwarna hijau tua dengan } \\
\text { panjang minimal } 50 \mathrm{~cm} \text {, kotiledon berwarna kuning } \\
\text { (berubah dari hijau muda ke kuning) dan terdapat } \\
\text { lingkaran putih seperti cincin pada hipokotil yang } \\
\text { berdekatan dengan perikarp. }\end{array}$ \\
\hline Rhizophora apiculata & $\begin{array}{l}\text { Propagul (hipokotil) berwarna hijau kecoklatan } \\
\text { dengan panjang minimal 20 cm dan diameter } \\
\text { minimal 14 mm, kotiledon berwarna coklat } \\
\text { kemerahan (berubah dari hijau muda ke coklat } \\
\text { kemerahan). Bagian bawah perikarp menggembung. }\end{array}$ \\
\hline Bruguiera gymnorrhiza & $\begin{array}{l}\text { Propagul (hipokotil) berwarna coklat kehijauan, } \\
\text { panjang minimal 20 cm }\end{array}$ \\
\hline Ceriops tagal & $\begin{array}{l}\text { Panjang propagul minimal 20 cm. Kotiledon berwarna } \\
\text { kuning dan mempunyai panjang 1 - 1.5 cm. }\end{array}$ \\
\hline Avicennia marina & $\begin{array}{l}\text { Buah berwarna putih dengan sedikit kuning, kulit } \\
\text { buah sedikit mengelupas. Berat biji minimal 1.5 gram } \\
\text { per biji. }\end{array}$ \\
\hline Buah berwarna coklat dengan sedikit kuning. \\
\hline Avicennia alba & $\begin{array}{l}\text { Buah berwarna hijau tua dan agak kecoklatan, } \\
\text { biasanya mengapung di air. }\end{array}$ \\
\hline Xylocarpus granatum & $\begin{array}{l}\text { Buah berwarna kuning kecoklatan dan mempunyai } \\
\text { retakan. Buah mengapung bila direndam di air. }\end{array}$ \\
\hline Sumbera alba & 999 \\
\hline
\end{tabular}

Sumber: Taniguchi et al. 1999 


\section{Teknik Pengolahan Hasil Hutan Bukan Kayu (HHBK) Mangrove}

Tanaman mangrove yang telah dewasa dan mampu menghasilkan buah dapat dimanfaatkan bahan bakunya untuk menjadi produk. Pemanfaatan hasil hutan mangrove oleh masyarakat lokal sebenarnya telah dilakukan sejak dulu dan merupakan salah satu kearifan lokal masyarakat sekitar ekosistem hutan mangrove. Namun dalam perkembangannya, hanya beberapa kawasan saja yang melakukan pengelolaan dan pemanfaatan mangrove secara intensif. Mengingat pentingnya peranan ekosistem hutan mangrove dalam keseimbangan ekosistem pesisir, maka diperlukan dorongan untuk mengelola dan memanfaatkan hasil hutan mangrove dengan tetap menjaga kelestarian ekosistem mangrove itu sendiri.

Jenis pemanfaatan ekosistem mangrove terbagi atas dua yaitu Hasil Hutan Kayu dan Hasil Hutan Bukan Kayu (HHBK). Pemanfaatan Hasil Hutan Kayu diantaranya sebagai bahan bangunan, kayu bakar, atau arang. Kayu mangrove memiliki banyak keunggulan dibandingkan dengan kayu dari pohon lain, karena mangrove dapat mengikat $\mathrm{CO}$ yang terdapat di atmosfer dan akan disimpan didalam kayu magrove. Oleh karena itu, arang dari kayu mangrove memiliki kualitas yang lebih baik dibandingkan arang yang terbuat dari jenis kayu dari tanaman darat. Namun, pemanfaatan Hasil Hutan Kayu tidak disarankan mengingat kondisi hutan mangrove yang telah mengalami kerusakan parah dan cenderung musnah, dikarenakan masyarakat memanfaatkan Hasil Hutan Kayu dengan mengeksploitasi secara besar-besaran.

Pemanfaatan mangrove lebih digalakkan pada sektor Hasil Hutan Bukan Kayu (HHBK) yaitu dengan memanfaatkan buah dan daun mangrove, pemanfaatan ekowisata, serta pemanfaatan silvofishery. Pemanfaatan Hasil Hutan Bukan Kayu masih membutuhkan dukungan dari berbagai pihak dengan tujuan untuk mengurangi penebangan hutan mangrove, namun pemanfaatan Hasil Hutan Bukan Kayu pada hutan mangrove masih kurang diminati dikarenakan berbagai kondisi, seperti Hasil Hutan Bukan Kayu dianggap sebagai produk sampingan sehingga jaminan kualitasnya masih diragukan, ketersediaan bahan baku masih rendah, inovasi pengolahan belum banyak dikuasai, dukungan teknologi belum memadai, dan secara ekonomi keuntungan masih rendah.

1. Sonneratia caseolaris (Pidada)

Buah Sonneratia caseolaris dapat dikonsumsi secara langsung dan non langsung. Secara langsung buah ini dapat dimakan sebagai campuran rujak. Secara non langsung buah ini dapat diolah menjadi sirup, selai, dodol, permen dan sabun. Buah ini memiliki kadar serat yang tinggi.

2. Bruguiera gymnorrhiza (Lindur)

Pemanfaatan buah ini harus melaui proses pengolahan untk menghilangkan rasa pahit pada buah. Buah ini dapat diolah menjadi tepung dan beras yang memiliki kadar karbohidrat tinggi yang setara dengan kentang.

3. Xylocarphus granatum (Nyirih)

Biji buah Nyirih dapat dimanfaatkan dan diolah menjadi lulur. Minyak dari bijinya dapat digunakan untuk minyak rambut. Bijinya juga memiliki manfaat sebagai obat luka, obat gatal dan pereda demam. Selain itu juga dapat digunakan secara oral untuk menyembuhkan penyakit kolera maupun diare. Air ekstraknya dapat digunakan untuk membersihkan luka. BPHM Wil. I, Bali mampu memproduksi olahan HHBK menjadi produk yang tidak diragukan lagi kualitasnya. 
Namun, menjadi kurang diminati dalam pasarannya karena produk yang dihasilkan tidaklah banyak. Meskipun BPHM Wil. I Bali mampu memberdayakan masyarakat lokal dalam melakukan pengolahan, namun belum dapat dilakukan secara kontinyu. Hal tersebut dikarenakan produk hasil olahan hanya dipasarkan dalam sebuah event, expo, maupun exhibition. Dengan demikian perlu mencari pangsa pasar yang utama untuk produk olahan mangrove agar produksi dan pengolahan dapat berlangsung terus menerus (continue) serta berkelanjutan (sustainable).

\section{KESIMPULAN DAN SARAN}

\section{Kesimpulan}

BPHM WIL I. Bali berperan penting dalam menjaga kelestarian dan keberlanjutan vegetasi Mangrove Tahura Ngurah Rai, melalui pemanfaatan potensi biotik mangrove. Salah satu upaya yang dilakukan adalah pengolahan terhadap Hasil Hutan Bukan Kayu (HHBK) mangrove, yaitu dapat berupa buah maupun daunnya.

Adapun jenis Sonneratia caseolaris, Bruguiera gymnorhiza, Xylocarpus granatum merupakan beberapa buah yang dapat dimanfaatkan menjadi sirup, dodol, sabun, tepung, beras, dan lulur.

\section{Saran}

Dari berbagai permasalahan tentang pengolahan Hasil Hutan Bukan Kayu (HHBK) Mangrove di Tahura Ngurah Rai dapat disarankan : (1) Koordinasi berbagai pemangku kepentingan dalam melakukan metode pengolahan HHBK sehingga dapat menjadi sebuah prosedur pengolahan yang dapat dipatenkan, (2) Pemberdayaan masyarakat lokal yang lebih memiliki skill dalam melakukan pengolahan, serta (3) Mematok pasar agar produk hasil olahan dapat berkelanjutan dan menjadi potensi ekonomi bagi masyarakat setempat.

\section{DAFTAR PUSTAKA}

Anwar, J., Danank, SJ., Hisyam, N., dan Anthony, AJ. 1984. Ekologi Ekosistem Sumatera. Gadjah Mada University Press. Yogyakarta.

Ardi, A. 1996. Studi Produktivitas Serasah dan Laju Dekomposisi Serasah di Tambak Tumpangsari Pola Empang Parit dengan Berbagai Komposisi Jenis Mangrove. Skripsi Jurusan Manajemen Hutan. Fakultas Kehutanan. IPB. Bogor.

Departemen Kehutanan, 1992. Hutan Bakau Indonesia. Penerbit Dephut. Jakarta

Ewusie, J.Y. 1990. Ekologi dan Biologi Tropika. Yayasan Obor Indonesia. Jakarta.

Istomo. 1992. Tinjuauan Ekologi Mangrove dan Pemanfaatannya di Indonesia. Lab. Ekologi Hutan. IPB. Bogor.

Kitamura, S: C. Anwar, A. Chaniago, S. Baba. 2003. Buku Panduan Mangrovedi Indonesia (Bali dan Lombok). Project Pengembangan Mangrove Berkelanjutan. Departemen Kehutanan Republik Indonesia dan Japan International Corporation Agency. 
Kusmana, C. 1993. A Study on Mangrove Forest Management Based on Ecological Data in East Sumatra Indonesia. Desertation at Faculty of Agriculture, Kyoto University, Japan.

Manurung, V.,T. Dan Sunarta, I.N. 2016. Konservasi Sumber Daya Taman Hutan Raya Ngurah Rai sebagai Destinasi Ekowisata. Jurnal Destinasi Pariwisata Vol. IV (2)

Soerianegara, I. 1964. Pengertian Produktivitas dalam Ekologi dan kemungkinannya dalam Penyelidikan Tumbuh-tumbuhan di Indonesia. Warta Penelitian Pertanian Volume 2. Lembaga Penelitian. Bogor.

Sugiarto dan W. Ekarianto. 1996. Ekosistem Lahan Basah di Indonesia. Asian Wetland dan PHPA. Bogor.

Sukardjo, S. 1985. Hutan Berair Melimpah di Indonesia. Oseana X (2) ; 62-77. 